\title{
Erratum
}

\section{Increased UDP-glucuronyltransferase \\ and gamma-glutamyltranspeptidase in enzyme-altered rat liver lesions produced by low doses of aflatoxin $B_{1}$}

\section{Gösta Fischer}

Institute of Pathology, University of Göttingen,

Robert-Koch-Straße 40, D-3400 Göttingen, Federal Republic of Germany

Virchows Arch [Cell Pathol] (1986) 51:445, 448

On page 445, the wrong units were given in the text preceding Eqs. (1) and (2). This section have read as follows:

The incidence of focal and nodular lesions (intersections $/ \mathrm{mm}^{2}$ see Table 1) is calculated from the equation:

$$
I=\frac{n}{S}
$$

The total area of intersections of AHF and $\mathrm{HN} / \mathrm{mm}^{2}$ of sectional plane (see Table 1) is obtained from the equation:

$$
A=\frac{\left(a_{1}+a_{2}+\ldots+a_{n}\right)}{S}(\%)
$$

Similarly, on page 448 Table 1 should have read as follows:

Table 1. Results of quantification of altered hepatic foci (AHF) and hyperplastic nodules (HN) demonstrated enzyme histochemically at different times after administration of aflatoxin

\begin{tabular}{|c|c|c|c|c|c|c|}
\hline \multirow{2}{*}{$\begin{array}{l}\text { Experimental } \\
\text { Protocol }\end{array}$} & \multirow[t]{2}{*}{ Days } & \multicolumn{2}{|c|}{ ATPase deficient lesions } & \multicolumn{3}{|c|}{$\gamma$-GT positive lesions } \\
\hline & & $\begin{array}{l}\text { Incidence of } \\
\text { intersections } \\
\text { of } \mathrm{AHF} \text { and } \mathrm{HN} \\
\left(\mathrm{No} / \mathrm{mm}^{2}\right)\end{array}$ & $\begin{array}{l}\text { Area of focal } \\
\text { and nodular } \\
\mathrm{N} \text { intersections } \\
(\%)\end{array}$ & \multicolumn{2}{|c|}{$\begin{array}{l}\text { Incidence of } \\
\text { intersections } \\
\text { of AHF and } \mathrm{HN} \\
\left(\mathrm{No} / \mathrm{mm}^{2}\right)\end{array}$} & $\begin{array}{l}\text { Area of focal } \\
\text { and nodular } \\
\text { intersections } \\
(\%)\end{array}$ \\
\hline \multirow[t]{3}{*}{ Model I } & 181 & $(0.098)^{\mathrm{a}}$ & $(0.852)$ & 0.12 & $(0.054)$ & $(0.988)$ \\
\hline & 308 & $(0.058)$ & $4.71 \quad(3.270)$ & 0.21 & $(0.037)$ & $(2.955)$ \\
\hline & 400 & $(0.090)$ & $13.11(16.140)$ & 0.24 & $(0.116)$ & $13.24(16.029)$ \\
\hline \multirow[t]{2}{*}{ Control I } & 210 & $(0.009)$ & $(0.024)$ & 0.01 & $(0.009)$ & $(0.009)$ \\
\hline & 308 & $(0.044)$ & $(0.674)$ & 0.02 & $(0.040)$ & $(0.170)$ \\
\hline \multirow[t]{3}{*}{ Model II } & 174 & $(0.038)$ & $(0.218)$ & 0.09 & $(0.052)$ & $(0.307)$ \\
\hline & 301 & $(0.053)$ & $(4.317)$ & 0.11 & $(0.046)$ & (4.374) \\
\hline & 400 & $(0.041)$ & $(7.928)$ & 0.22 & $(0.125)$ & $(7.513)$ \\
\hline \multirow[t]{2}{*}{ Control II } & 214 & $0.003(0.005)$ & $(0.010)$ & 0.01 & $(0.008)$ & $(0.013)$ \\
\hline & 326 & $0.01 \quad(0.010)$ & $(0.020)$ & 0.00 & $(0.000)$ & $(0.000)$ \\
\hline
\end{tabular}
$\mathrm{B}_{1}$

a The mean values of 4 determinations are listed. The standard deviations are given in parentheses 